Kieft, R.A.M.M., Stalpers, D., Jansen, A.P.M., Francke, A.L., Delnoij, D.M.J. The methodological quality of nurse-sensitive indicators in Dutch hospitals: a descriptive exploratory research study? Health Policy: 2018, 122(7), 755-764

\begin{tabular}{|l|l|}
\hline $\begin{array}{l}\text { Postprint } \\
\text { Version }\end{array}$ & 1.0 \\
\hline $\begin{array}{l}\text { Journal } \\
\text { website }\end{array}$ & https://linkinghub.elsevier.com/retrieve/pii/S0168851018301647 \\
\hline Pubmed link & $\underline{\text { https://www.ncbi.nlm.nih.gov/pubmed/29880398 }}$ \\
\hline DOI & $10.1016 /$ j.healthpol.2018.05.015 \\
\hline
\end{tabular}

This is a NIVEL certified Post Print, more info at http://www.nivel.eu

\title{
The methodological quality of nurse-sensitive indicators in Dutch hospitals: A descriptive exploratory research study
}

\author{
R.A.M.M.KIEFT ${ }^{\mathrm{A} D}$ D.STALPERS ${ }^{\mathrm{BA}}$.P.M.JANSEN ${ }^{\mathrm{A}}$ A.L.FRANCKE ${ }^{\mathrm{CD}}$ D.M.J.DELNOIJ ${ }^{\mathrm{EF}}$
}

\section{HighLIGHTS}

- Mandatory nurse-sensitive indicators are used to monitor care in Dutch hospitals.

- It is important to strengthen the development of a suitable set.

- The methodological quality of nurse-sensitive indicators is assessed in this paper.

- In general, the methodological quality was evaluated as low to moderate.

- The results provide opportunities to improve the development of nurse-sensitive indicators.

\begin{abstract}
Objective: Nurse-sensitive indicators (NSIs) are increasingly being developed and used to establish quality of nursing care in Western countries. The objective was to gain insights into the methodological quality of mandatory NSIs in Dutch hospitals, including indicators for pain, wound care, malnutrition and delirium.

Design: A descriptive exploratory design was used, starting with desk research into publicly available documents and reports describing the development of the NSIs included in this study. We used the validated Appraisal of Indicators through Research and Evaluation (AIRE) instrument to evaluate the methodological quality. Results: Although the purpose and relevance of each individual NSI have been described, no detailed information about the criteria for selecting these topics is available. It is not clear which specific stakeholders participated and how their input was used. We found no information about the process of collecting and compiling scientific evidence. It is unclear whether and to what extent the usability of NSIs has been tested.

Conclusion: The methodological quality of NSIs used in Dutch hospitals is less than optimal in various ways and it is therefore questionable if the indicators are accurate enough to identify changes or improve nursing practice. Our study also provides an example of how the methodological quality of NSIs can be assessed systematically, which is relevant considering the increasing use of NSIs in various countries.
\end{abstract}


Kieft, R.A.M.M., Stalpers, D., Jansen, A.P.M., Francke, A.L., Delnoij, D.M.J. The methodological quality of nurse-sensitive indicators in Dutch hospitals: a descriptive exploratory research study? Health Policy: 2018, 122(7), 755-764

\section{INTRODUCTION}

Nurses collect information in order to monitor the health status of patients, their functioning or well-being

[1]. For instance, when a patient is immobile nurses examine the patient's skin to identify whether pressure ulcers may be present. With that information nurses can determine what interventions are appropriate. If the assessment is repeated on a regular basis, the assessment scores or outcomes will help nurses to monitor whether the patient is developing a pressure ulcer or whether the stage of the existing pressure ulcer is improving. In addition, nurses can evaluate the effectiveness of their interventions or actions by calculating the actual pressure ulcer incidence at the unit level. It is then possible to compare the results between the units or even between organisations and determine which unit or organisation has the highest or lowest incidence. This information lets nurses evaluate the quality of nursing care.

To determine the state or quality level of nursing care, nurse-sensitive indicators (NSIs) are developed. NSIs are quantifiable items that monitor or give an indication of the quality of the nursing care provided [2]. 'Nurse-sensitive' means that the NSI scores are actually affected or influenced by nurses [3], [4]. The quantifiable items can be calculated as a numerator and denominator. The numerator refers to the outcome of interest (e.g. the incidence of pressure ulcers at the unit level) and the denominator refers to the population at risk (e.g. the number of patients at the unit level). An NSI score needs to encapsulate aspects related to nursing practice and can be used to determine how a unit or an organisation is performing against a certain threshold or norm [5]. An increasing number of studies have identified NSIs for monitoring the quality of nursing care [6], [7], [8], [9], [10] such as fatigue

[6] or pressure ulcers [10]. Although the selection of NSIs can vary between healthcare sectors or contexts, the NSI scores are used for improving internal quality and external accountability. Internal quality improvement means that nurses evaluate nursing care and can visualise their contribution to patient outcomes [4], [11]. Nurses can share and compare nursing quality internally or with other healthcare organisations, which helps identify and understand problems and formulate improvement goals. NSI scores are used for encouraging nursing professionals and organisations to improve performance at the macro (population) and micro (patient) levels [12].

External accountability is about how healthcare quality regulators (e.g. national quality commissions or healthcare inspectorates) control the functioning of the healthcare system and evaluate the impact of policies [13]. External accountability also covers governmental quality regulation, pay-for-performance contracts or consumer information [12], [13]. In this case, NSI scores are needed to evaluate 'return on investment', to enable selective contracting or to help consumer choice.

In a review of measurable nursing quality information, Boo \& Froelicher [14] and Magee et al. [15] have indicated that nursing information is used for different internal and external purposes. In order to compare and improve nursing care, attention needs to be paid to the methodological quality of NSIs [16], [17]. The methodological quality refers to the development process and application of NSIs. The development describes the process in which scientific evidence is collected and compiled, for instance to strengthen the link with nursing care and patient outcomes or to demonstrate consistency of results across studies. The application implies the extent to which consistent, reliable and valid information is available [18], [19]. It means that the NSI specification should be accompanied by clear and precise instructions [20]. The unit of analysis should be 
Kieft, R.A.M.M., Stalpers, D., Jansen, A.P.M., Francke, A.L., Delnoij, D.M.J. The methodologica/ quality of nurse-sensitive indicators in Dutch hospitals: a descriptive exploratory research study? Health Policy: 2018, 122(7), 755-764

specified, as well as the target group and inclusion and exclusion criteria. The NSI should be piloted in practice to test data collection methods and to test if nurses can routinely collect information [16].

Over the past two decades various sets of NSIs have been identified and implemented in various Western countries. For example, in the United States the National Quality Forum (NQF) has developed fifteen NSIs including standardised performance measures to evaluate the quality of nursing care [21], [22]. The measures were identified through a consensus development process involving various healthcare stakeholders. The NSIs are incorporated in a national database of nursing quality indicators (NDNQI), that provides quarterly or annual information about nursing care at unit level [23]. Examples of included NSIs are pressure ulcer prevalence, patient falls and falls with injury. In Canada a similar initiative has been set up, resulting in a Canadian Health Outcomes for Better Information and Care (C-HOBIC) project focussed on the collection of standardised patient outcomes reflective of nursing practice [24]. Various stakeholders, among others, the Canadian Nurses Association and Ontario's Ministry of Health and Long-Term Care supported the project. Patient outcomes related to functional status, self-care, symptom management and safety have been defined, including standardised measurements and empirical evidence linking them to nursing interventions [25]. The collection of outcomes and related (nursing) data provide information about the quality of nursing care. In Scotland the National Health Service (NHS) developed a national set of NSIs to evaluate the quality of nursing care, including the incidence of healthcare associated pressure ulcers, provision of nutritional screening and care planning and the incidence of healthcare associated pressure ulcers [26]. In Ireland a Framework for National Performance Indicators for Nursing and Midwifery has been developed in collaboration with the Irish Health Services, including pressure ulcer incidence and falls incidence [27].

In the Netherlands the development and implementation of quality indicators to enhance quality of care is supported by the Dutch Government [28], [29]. The Healthcare Inspectorate (linked to the Dutch Ministry of Health, Welfare and Sport) has developed a national supervision programme to identify areas where there are potential risks to the quality of hospital care. Since 2012, the Dutch Nurses' Association (V\&VN) has been officially involved in the Inspectorate programme and is responsible for the NSI development process. This involves structural consultations with various departments of the Dutch Nurses' Association in which nursing professionals are represented. Nursing professionals with knowledge or expertise are also involved, depending the subject and aim of the NSI, and mandated to make decisions and approve the final draft NSIs. After approval by nursing professionals and experts, the NSI is submitted to the Inspectorate programme's committee and formally approved. The Inspectorate programme includes NSIs related to wound care, malnutrition, delirium and pain [30]. Hospitals are obliged to provide the information requested. The government can use the results to take actions or develop and adjust policy and strategy to improve nursing care [28]. For that reason, it is important to maintain efforts to strengthen the development and use of suitable NSIs. In this study we focused on the methodological quality of the mandatory Dutch NSIs related to inpatient hospital care and how that quality was assessed.

\subsection{Study question}

What is the methodological quality of the mandatory NSIs for Dutch hospitals? 
Kieft, R.A.M.M., Stalpers, D., Jansen, A.P.M., Francke, A.L., Delnoij, D.M.J. The methodologica/ quality of nurse-sensitive indicators in Dutch hospitals: a descriptive exploratory research study) Health Policy: 2018, 122(7), 755-764

\section{METHOD}

\subsection{Research design}

A descriptive exploratory design to assess the methodological quality of mandatory Dutch NSIs.

\subsection{Composition and data collection}

In order to assess the methodological quality, four researchers and nursing experts (RK, $\mathrm{AJ}, \mathrm{IvP}$ and $\mathrm{MH}$ ) identified and collected relevant publicly available documents and reports, such as policy documents, programme evaluation reports, publications and benchmarks from stakeholders, governmental agencies and regulatory authorities (Healthcare Inspectorate) and reports on websites (www.vmszorg.nl;www.igz.nl;www.venvn.nl;www.demedischspecialist.nl;www.nfu.nl;h ttp://www.ziekenhuizentransparant.nl/;http://fightmalnutrition.eu/).

Documents, reports and benchmarks up to 2015 were included if the development or implementation process of NSIs related to inpatient hospital care was described. Policy, accountability and evaluation reports about the programme itself were also included (up to 2015).

The four researchers then assessed the methodological quality of the selected NSIs. There are various instruments for evaluating methodological quality, such as the Guidance for Evaluating Evidence and Measure Testing from National Quality Forum [19], the Guide to Inpatient Quality Indicators [31] or the Dutch validated Appraisal of Indicators through Research and Evaluation instrument, abbreviated as AIRE instrument [32]. However, the first two instruments mentioned focus on evaluating measurements or measures rather than quality indicators. The AIRE instrument appeared to be more appropriate for this study, as it is primarily intended for assessing the methodological quality of existing quality indicators and their development paths. Previous studies in the Netherlands also assessed the methodological quality of quality indicators using the AIRE instrument [33], [34], [35]. In those studies, the instrument was found to be suitable for assessing the development process of quality indicators, including NSIs. The AIRE instrument consists of four domains [32]:

- Purpose, relevance and organisational entity.

- Stakeholder involvement in the development process.

- Scientific evidence.

- Additional evidence, formulation and usage.

Each domain contains several items, giving 20 in all (see Table 1). Each item has a score ranging from 1 ('strongly disagree') to 4 ('strongly agree') [32].

\section{[TABLE 1]}

\subsection{Data analysis}

Prior to the appraisal, the four researchers (RK, AJ, IvP and MH) studied and reviewed the documents and reports that had been included [28], [29], [30]. The methodological quality of the mandatory NSIs was then evaluated (see Table 2 for an overview of the mandatory NSIs).

\section{[TABLE 2]}

Four researchers (RK, AJ, IvP and $\mathrm{MH}$ ) completed the AIRE instrument independently, separately for each NSI. The scores were based on knowledge extracted from the documents and reports studied. The scores were put in an Excel file. 
Kieft, R.A.M.M., Stalpers, D., Jansen, A.P.M., Francke, A.L., Delnoij, D.M.J. The methodologica/ quality of nurse-sensitive indicators in Dutch hospitals: a descriptive exploratory research study? Health Policy: 2018, 122(7), 755-764

The item scores of each NSI were converted to the domain level by a standardised calculation procedure.

First, the maximum possible score for a domain was calculated by multiplying the maximum score per item (a score of 4 ) by the number of items in that domain and the number of researchers. The minimum possible score was calculated using the same procedure, except with a minimum score per item (a score of 1). The standardised domain score is the s score obtained per domain minus the minimum possible score for that domain \} divided by \{the maximum possible score minus the minimum possible score , all times $100 \%$ [32]. An example of the calculation procedure is set out in Fig. 1.

\section{[FIGURE 1]}

One researcher (IvP) entered the data and calculated the scores while another researcher (RK) cross-checked the data entry and calculations. Both the item and domain scores were placed in a table. Because no guidance was available on how to interpret the scores, this study arbitrarily defined domain scores of between 0 and $33 \%$ as low methodological quality, 34-66\% as moderate and $67-100 \%$ as high. The results were clarified by following the domains of the AIRE instrument. The scores supported the researchers (RK, DD, DS) in their analysis and discussion.

To measure the interrater reliability we performed a weighted kappa test. First we calculated Cohen's kappa between two researchers. Then an average over all pairs of researchers was calculated (researcher $1 \times 2$, researcher $1 \times 3$, researcher $1 \times 4$, researcher $2 \times 3$, researcher $2 \times 4$, researcher $3 \times 4$ ). Degrees of agreement were categorised as follows: $\mathrm{k}$ of $0.2-0.4$, fair agreement; $\mathrm{k}$ of $0.4-0.6$, moderate agreement; $\mathrm{k}$ of $0.6-0.8$, substantial agreement; and k of 0.8-1.0, almost perfect agreement.

\section{RESULTS}

The methodological quality of NSIs was assessed with the AIRE instrument. The domain scores are presented in Fig. 2. The item scores of each NSI are presented in Appendix A in Supplementary materials.

\section{[FIGURE 2]}

In general, according to the researchers, domain 1 has a moderate methodological quality (with a range of 52\%-55\%) as shown in Fig. 2. This also applies for domain 2, except for the scores of both malnutrition NSIs, for which the methodological quality is low. Domain 3 (with a range of $11 \%-36 \%$ ) and domain 4 (with a range of $18 \%-40 \%$ ) tend towards low methodological quality. The NSI screening for malnutrition has the lowest scores (a range of 11\%-52\%). Interrater agreement between the researchers was substantial with Cohen's kappa values of $\mathrm{k}=0.6$ to 0.8 for four NSIs (wound expertise centre, diabetic foot, screening malnutrition, pain) and moderate with $\mathrm{k}$ values of $0.4-0.6$ for the remaining NSIs (see Appendix A in Supplementary materials). The results are explained in the following section.

\subsection{NSI 'Wound expertise centre'}

\subsubsection{Purpose, relevance and organisational entity}

This NSI has been in the basic set of the Inspectorate programme since 2013. It refers to whether a hospital involves or has access to a wound expertise centre. The criterion for 
Kieft, R.A.M.M., Stalpers, D., Jansen, A.P.M., Francke, A.L., Delnoij, D.M.J. The methodologica/ quality of nurse-sensitive indicators in Dutch hospitals: a descriptive exploratory research study) Health Policy: 2018, 122(7), 755-764

selecting this NSI is that different professionals and disciplines are involved in caring for patients with (chronic) wounds, resulting in inefficient treatment of wounds. The consequence is a delay in effective treatment or admission to a hospital or residential care. The expectation is that involving a wound expertise centre will lead to better wound healing and improved quality of life and well-being. The description does not provide information about which healthcare processes are covered by the NSI.

\subsubsection{Stakeholder involvement}

The accompanying description of the indicator states that professionals of the Wound Care department of the Dutch Nurses' Association (V\&VN) and the Wound Care Consultant Society (WCS) were involved in the development process. No information has been found about the reasoning for selecting these professionals and their specific expertise or if and why other stakeholders such as patients' representatives were not involved.

\subsubsection{Supporting scientific evidence}

The statements are supported with references from scientific evidence of a study on 'leg ulcer clinics in Britain', although only the name of the author and publication year are given (for example: Moffat 1992). No further information is available in the accompanying description of the indicator.

\subsubsection{Additional evidence, formulation and usage}

The indicator itself consists of a single question: 'Does the hospital have access to a wound expertise centre'? It is not clear if the indicator has been piloted in the Netherlands. The efforts needed to set up a wound expertise centre have not been described. Features of a wound expertise centre are described in the accompanying description of the indicator.

\subsection{NSI 'Diabetic foot classified by the Texas classification'}

\subsubsection{Purpose, relevance and organisational entity}

The NSI refers to the number of patients with a diabetic foot classified by the Texas classification. The reasoning behind the selection of this classification is described as follows (basic set 2015; p. 71):

'There are various international classification systems. The Wagner and Texas classifications are the best-known. In the consensus text from 1998, the Dutch classification has also been described. The classification is included in the basic set because the Texas classification has been validated internationally'.

As mentioned in the accompanying description of the indicator, the main reason for developing this NSI is that one uniform registration system is a requirement in order to monitor how many patients with a diabetic foot are treated and to provide insights into the various grades of diabetic foot. The analyses are at the hospital level.

\subsubsection{Stakeholder involvement}

Although it is stated in the accompanying description of the indicator that professionals are involved in the development process, it does not say which professionals. No information has been found about the involvement of stakeholders (e.g. patients or insurers). 
Kieft, R.A.M.M., Stalpers, D., Jansen, A.P.M., Francke, A.L., Delnoij, D.M.J. The methodologica/ quality of nurse-sensitive indicators in Dutch hospitals: a descriptive exploratory research study? Health Policy: 2018, 122(7), 755-764

\subsubsection{Supporting scientific evidence}

No references to scientific evidence about the Texas classification have been included or supporting evidence that a single registration system will provide more insights into how many patients with a diabetic foot are treated.

\subsubsection{Additional evidence, formulation and usage}

No definition of a diabetic foot was found in the accompanying explanation of the NSI. The diagnosis process for a diabetic foot as well as the care process and responsibilities are not described. It is also not clear which patients should be included or excluded. The indicator itself consists of nine questions, which are specified in Table 3. It is not clear if the NSI has been piloted in practice. The efforts needed to ensure that nurses can work with a single registration system have not been described.

\section{[TABLE 3]}

\subsection{NSI 'Screening for malnutrition'}

\subsubsection{Purpose, relevance and organisational entity}

The accompanying description refers to the extent to which patients are systematically screened for malnutrition and monitoring to ensure malnourished patients are treated appropriately and in time. Malnutrition is defined as:

- Children (28 days - 1 year) weighing 2 SDs or more below the average weight-to-age growth curve

- Children (1-<18 years) weighing 2 SDs or more below the average weight-to-height growth curve

- Adults ( $\geq 18$ years) with a SNAQ score on admission of $\geq 3$ or a MUST score of $\geq 2$

The reasoning behind the selection of this indicator is that the prevalence of malnutrition in hospitals is high (20-40\% of adults and children) and that malnourishment in patients may be undetected and untreated. The analysis is at the hospital level.

\subsubsection{Stakeholder involvement}

There is no statement of which professionals with specific expertise of paediatric nutrition and malnutrition were involved in the development process. No information has been found to state whether stakeholders were involved.

\subsubsection{Supporting scientific evidence}

It is not clear if systematic methods were used to search for scientific evidence. In the accompanying description, the statements about the purpose and relevance are not supported with references from evidence-based guidelines or scientific evidence from studies published in peer-reviewed scientific journals. The Screening Tool Risk On Nutritional Status and Growth (STRONGkids) was used for determining whether each case involves acute malnutrition. It is not clear if this is based on recommendations from a guideline or scientific evidence. A reference with a link to the Dutch malnutrition steering group is given. This gives more information about malnutrition.

\subsubsection{Additional evidence, formulation and usage}

The numerator and denominator are specified in Fig. 3. The target group is children aged between 28 days and 18 years. Each child needs to be assessed upon admission. Children 
Kieft, R.A.M.M., Stalpers, D., Jansen, A.P.M., Francke, A.L., Delnoij, D.M.J. The methodologica/ quality of nurse-sensitive indicators in Dutch hospitals: a descriptive exploratory research study? Health Policy: 2018, 122(7), 755-764

in outpatient settings and infants younger than 28 days are excluded. The accompanying description does not specify how the scores of the STRONGkids tool need to be documented nor how the counting process should be conducted (e.g. prevalence or continuous measurement). Following the link to the malnutrition steering group did not reveal any specific instructions about the instrument and how to interpret the results. It is not clear if the NSI has been piloted in practice and if the indicator has sufficient discriminative power. The accompanying description refers to one study that investigates the feasibility and value of STRONGkids.

\section{[FIGURE 3]}

\subsection{NSI 'Treatment of malnutrition'}

\subsubsection{Purpose, relevance and organisational entity}

The accompanying description states that malnourished patients should be treated appropriately and in good time, meaning that malnourished patients should receive dietary treatment within $48 \mathrm{~h}$. It states that untreated malnutrition increases postoperative morbidity, prolonged hospitalisation, premature death and delayed wound healing. The analysis is at the hospital level.

\subsubsection{Stakeholder involvement}

It was not stated which professionals with specific expertise of (paediatric and other) nutrition and malnutrition were involved in the development process. No information was found about whether stakeholders had been involved.

\subsubsection{Supporting scientific evidence}

It is not clear if systematic methods were used to search for scientific evidence. In the accompanying description, the statement that patients should receive dietary treatment within $48 \mathrm{~h}$ is not supported with references from evidence-based guidelines or scientific evidence from studies published in peer-reviewed scientific journals.

\subsubsection{Additional evidence, formulation and usage}

The numerator and denominator are specified in Fig. 3. The target group of indicator 2a (Fig. 3) is adults with severe malnourishment, though without specifying what 'severe' means. A protein intake norm has been specified. The target groups of indicators $2 b$ and 2c (Fig. 3) are acutely malnourished children aged $>1$ year. Inclusion or exclusion criteria are not mentioned. An adequate intake has been defined.

There is no specification of how the protein or energy intake (adults and children) should be described or specified and how often it needs to be documented. The accompanying description states that the counting for all included malnourished patients should be based on the intake on the fourth day of admission of each malnourished patient. This intake can be assessed on the fifth day of admission. The outcome of the indicator is the number of patients with an adequate intake (protein or energy). It is not clear if the NSI has been piloted in practice, if the efforts to collect information have been considered and if the indicator has sufficient discriminative power.

\subsection{NSI 'Risk assessment for delirium'}

\subsubsection{Purpose, relevance and organisational entity}


Kieft, R.A.M.M., Stalpers, D., Jansen, A.P.M., Francke, A.L., Delnoij, D.M.J. The methodologica/ quality of nurse-sensitive indicators in Dutch hospitals: a descriptive exploratory research study) Health Policy: 2018, 122(7), 755-764

The purpose of this NSI is to develop a standardised assessment and treatment for delirium. The reason for selecting this NSI is that delirium is associated with an increased length of stay, complications during stay, increased hospital mortality and decreased functional recovery of the underlying disease. The analysis is at the hospital level.

\subsubsection{Stakeholder involvement}

There is no statement of which professionals with specific expertise in delirium or which stakeholders were involved in the development process.

\subsubsection{Supporting scientific evidence}

The statements are not supported with references from evidence-based guidelines or scientific evidence from studies published in peer-reviewed scientific journals. Within the specification of the indicator, there are no references to scientific evidence from studies published in peer-reviewed scientific journals.

\subsubsection{Additional evidence, formulation and usage}

The NSI refers to the percentage of nursing wards assessing the risk of delirium (Fig. 4).

\section{[FIGURE 4]}

A definition of delirium is described and based on the 'Diagnostic and statistical manual of mental disorders' (DSM-IV) criteria for delirium, which include a reference. The target group is elderly patients (70-plus). Every patient aged 70 or older needs to be assessed upon admission to hospital. Inclusion and exclusion criteria are not mentioned. The risk assessment for delirium consists of three questions:

- Do you have memory problems?

- Did you need help with anything in the last $24 \mathrm{~h}$ ?

- Did you have periods of confusion during a previous admission or sickness?

A patient has a high risk of developing delirium if one or more positive answers are given. Although it is stated that the assessment scores should be documented structurally, it does not specify how the assessment scores need to be documented.

\subsection{NSI 'Screening for and observation of delirium'}

\subsubsection{Purpose, relevance and organisational entity}

The purpose of this NSI is to develop a standardised assessment and treatment for delirium.

\subsubsection{Stakeholder involvement}

There is no statement of which professionals with specific expertise in delirium or which stakeholders were involved in the development process.

\subsubsection{Supporting scientific evidence}

The statements are not supported with references from evidence-based guidelines or scientific evidence from studies published in peer-reviewed scientific journals. Within the specification of the indicator, there are no references to scientific evidence from studies published in peer-reviewed scientific journals.

\subsubsection{Additional evidence, formulation and usage}


Kieft, R.A.M.M., Stalpers, D., Jansen, A.P.M., Francke, A.L., Delnoij, D.M.J. The methodologica/ quality of nurse-sensitive indicators in Dutch hospitals: a descriptive exploratory research study) Health Policy: 2018, 122(7), 755-764

The NSI refers to the percentage of patients with a risk of developing delirium who have been screened and observed for the presence of delirium. The target group is elderly people (70 and older) with a confirmed high risk of developing delirium.

In the accompanying description, it is not specified how and how often the assessment scores need to be documented. It is noted that the patients included should be counted once per quarter (four times a year). The outcome of the indicator is the average of the four quarterly counts.

\subsection{NSI 'Hospital-wide patient standardised pain assessment'}

\subsubsection{Purpose, relevance and organisational entity}

The NSI refers to hospital-wide standardised pain assessment for the entire patient population, including patients with cancer. The reason for selecting this indicator is that accurate and timely pain assessment can prevent complications and influence patient wellbeing and recovery.

The transition to hospital-wide standardised pain assessment will be supervised in three phases. First, the preconditions for establishing hospital-wide standardised pain assessment will be monitored. The second phase will focus on recording pain scores and the final phase is monitoring the actions and results following the pain scores. The purpose of this NSI is related to the first phase. The analysis is at the hospital level.

\subsubsection{Stakeholder involvement}

There is no statement of which professionals with specific expertise of pain or which stakeholders were involved in the development process.

\subsubsection{Supporting scientific evidence}

The statements are not supported with references from evidence based guidelines or scientific evidence from studies published in peer-reviewed scientific journals.

\subsubsection{Additional evidence, formulation and usage}

The indicator consists of three questions:

- Does the hospital have a hospital-wide protocol for detecting and treating pain that is used by relevant non-surgical units?

- Does the hospital have a pain service team for non-surgical patients?

- Do professionals have access to hospital-wide electronic medical records in which pain scores can be documented?

In the description accompanying this indicator, there is no definition of 'pain'. In the description accompanying the indicator, no explanation or definition of a 'pain service team' is provided either.

\section{DISCUSSION}

This study aims to evaluate the methodological quality of mandatory NSIs in Dutch hospitals, including those for wound care, malnutrition, delirium and pain. The methodological quality was assessed using the AIRE instrument.

\subsection{Purpose, relevance and organisation entity}

Although the purpose and relevance of each individual NSI have been described, no detailed information about the criteria for selecting these topics or the organisational 
Kieft, R.A.M.M., Stalpers, D., Jansen, A.P.M., Francke, A.L., Delnoij, D.M.J. The methodologica/ quality of nurse-sensitive indicators in Dutch hospitals: a descriptive exploratory research study? Health Policy: 2018, 122(7), 755-764

context of the NSIs is available. It is therefore not clear if the healthcare processes of each NSI are covered sufficiently and if the NSI scores actually reflect the quality of nursing care. This is a relevant question, because the NSI scores need to identify areas for nursing practice improvements or distinguish differences between hospitals [16]. Comparing the list of Dutch NSIs against existing NSIs in other countries, we found that the National Health Service of Scotland has developed a similar national set of NSIs applicable for the inpatient hospital setting, namely 'pressure ulcer prevention', 'falls', 'food, fluid and nutrition' and 'monitoring and observation' [36]. The National Quality Forum (NQF) has set up a Nurse-sensitive Care Measure Set that comprises fifteen measurements [22], which to our knowledge are not mandatory for hospitals but included in the NDNQI. However, none of the Dutch NSIs included match the NQF list. One possible explanation for this might be that the criteria and relevance for selecting the topics of national NSIs differ. For instance, the area identified might have a large impact on a national population or it might have a potential cost-saving rationale. Furthermore, it is arguable whether the NSI 'Diabetic foot classified by the Texas classification' is truly an NSI. Its purpose is to monitor if language has been used uniformly. There is an argument that a well-functioning monitoring system can only operate if nurses define the nursing information collected unambiguously and uniformly. In this case, using uniform terminology is a precondition for all NSIs [20]. This precondition of using an uniform terminology is adopted in the C-HOBIC project in Canada.

However, the findings of our study may help us to understand that identifying and defining of NSIs is not straightforward.

\subsection{Stakeholder involvement in the development process}

It could be argued that the choice and inclusion of an NSI in a national basic set has to do with different stakeholders' perspectives (e.g. patients, healthcare providers or health insurers) [37]. Although the accompanying descriptions with the basic NSI set state that relevant stakeholders are involved, it is not clear if a stakeholder analysis has been performed. No information is available about which specific stakeholders are of interest, why, how they participated in the development of the NSI and how their input was used. There is for instance no description of whether patients' experiences or perspectives were consulted to determine priorities in the selection of the NSI. However, the findings of our study correspond with those of Kötter et al. [38] who showed that the input of patients (or patient representatives) were consistently not reported in the publications retrieved and that little is known about the effects of patients' (or patient representatives') involvement in the selection and development of NSIs. Considering the differences in information needs of stakeholders, it is recommended that their views should be taken into account in order to strengthen the rationales behind the selection of an NSI [37].

\subsection{Scientific evidence}

When reviewing the results of scientific evidence, we found no information about the process of collecting and compiling scientific evidence. Neither was there a summary or a critical appraisal of the quantity or quality of the underlying evidence. It is not clear whether a literature search was performed to identify if and why the NSIs are nursesensitive, how they are linked to outcomes and why they have been included.

Outcome indicators sensitive to nursing care can have different perspectives. For instance, from an economic perspective, an increased length of stay is only acceptable if it adds value for patients. NSIs related to adverse events will focus on complications during the hospital stay, such as falls or mortality [39]. It is also important to take 
Kieft, R.A.M.M., Stalpers, D., Jansen, A.P.M., Francke, A.L., Delnoij, D.M.J. The methodological quality of nurse-sensitive indicators in Dutch hospitals: a descriptive exploratory research study? Health Policy: 2018, 122(7), 755-764

account of the context to which the NSI applies, because the NSI scores can be influenced by patient variables (e.g. age or comorbidity), organisational variables (e.g. working environment [40]) and nursing variables (e.g. education) [3]. A summary or a critical appraisal of the underlying evidence should be available [16] in order to explain potential variation in the NSI scores of hospitals.

\subsection{Additional evidence, formulation and usage}

It is unclear whether and to what extent the usability of NSIs has been tested, or if the NSIs are accurate enough to identify changes in nursing practice. It seems for instance that the numerator and denominator of the indicator measuring malnutrition are highly impracticable: the energy or protein intake has to be calculated on the fourth and fifth admission day of each malnourished patient. Who monitors and reports how many days patients have been hospitalised? What should be done when a patient is transferred to another nursing ward? Imprecise technical specifications might be a potential cause of inaccurate data collection. In the Netherlands, hospitals can participate in various programmes, e.g. a national safety management programme or the National Prevalence Measurement of Quality of Care (the LPZ), both collecting data. Hospitals might use this information for different purposes. The national safety management programme has been launched to prevent or reduce healthcare-related accidents and adverse events. It entails implementing a safety management system for eleven themes, including malnutrition, delirium and pain [41], [42]. The National Prevalence Measurement of Quality of Care has defined several NSIs, including malnutrition and pain [43]. Looking at e.g. the criteria for diagnosing malnutrition, the safety programme uses the following definition: 'Body mass index $<=20$ (patients affected by COPD $<21$ ); and/or $>10 \%$ unintentional weight loss in the past six months; and/or $>5 \%$ unintentional weight loss in the past month' [42]. According to the LPZ a malnourished patient has a 'BMI $<18.5$ (patients older than 65 BMI $<20$ ); and/or unintentional weight loss of more than $10 \%$ in the past six months' [44]. These definitions differ from the definition of the national mandatory NSI 'malnutrition'.

Burston et al. [4] have discussed how standardisation of definitions is one condition for allowing comparison of NSI scores. Moreover, looking at the concept of an NSI, Heslop et al. [2] argued that theory building with clarified concepts and their underlying relationships is needed. Heslop et al. [2] found different terms and definitions for the concept of an NSI (e.g. outcome indicators/measurements, performance indicators). It is possible that the lack of a clear definition of the concept itself and variations in categories might lead to differences into the development process of NSIs.

The international debate on NSIs focusses not only on the development and methodological quality of indicators, bus also on the collection of data used to calculate NSI scores. Nurses operate in a complex healthcare context with organisation policies that are focussed on cost-efficiency, transparency and (professional) accountability goals [45]. Nursing characteristics (e.g. skill mix) or patient characteristics (e.g. comorbidity, age) might influence patient outcomes as well. To reduce the possibility of incorrect interpretations, data needs to be unambiguous. It means that data should have a single clearly defined meaning. The need for unambiguous nursing data is a topic of increased debate, particularly in relation to the use of electronic health records (EHR). EHR are considered as 'primary/source data', meaning that the data is used for monitoring patients' health or functioning problems, nursing interventions, and patient outcomes in direct patient care. This primary/source data can be used for 'secondary purposes' such as scientific research, public health monitoring or quality control [46]. Both for direct 
Kieft, R.A.M.M., Stalpers, D., Jansen, A.P.M., Francke, A.L., Delnoij, D.M.J. The methodological quality of nurse-sensitive indicators in Dutch hospitals: a descriptive exploratory research study? Health Policy: 2018, 122(7), 755-764

patient care as well as for secondary use, the quality of primary/source data should be consistent and unambiguous. This is one of the starting points of the Canadian C-HOBIC project, which focusses on implementing unambiguous patient outcome data related to nursing care in an EHR [24]. Comparability and interoperability of primary/source data is a necessity for secondary use of data. According to Hovenga [47]. we need to understand 'what is required of data and systems to achieve the desired outcomes across our data and systems' ([47]; page 29). In a literature review, Galster [48] found that data is duplicated instead of being reused, because it is considered as inadequate, not available or accessible. Hoi [20] stated that NSIs and measurement methodology should incorporate unambiguous data so nurses' contribution to quality of care can be investigated in a reliable and valid manner. An infrastructure to develop, implement and govern nursing data nationwide to integrate nursing data into EHR's would be valuable [47]. In order to facilitate international learning, however, such a national infrastructure would have to use internationally accepted terminologies (e.g. SNOMED CT).

\subsection{Research implications}

This study has raised questions about the methodological quality of the NSIs used in Dutch hospitals. We expected to find a scientific basis for the selected indicators, including published research or documents describing the scientific basis and explaining the reasoning behind the selection and development of indicators. However, we found that this information is lacking or at least not made public. That in itself is already a relevant finding. To ensure quality related to the collection of nursing data and consistently measure nurses' performance, it is important to gain knowledge and insight into the methodological quality of the existing nursing-sensitive set of indicators. This knowledge can be gathered by making scientific opinions, reports, or similar documentation publicly available. Our study might also have added value for experts and clinicians in other countries who are involved in development, selection or implementation of NSIs, since we showed how the methodological quality can be established and discussed.

If we aim to use data to improve quality of care, it is important to maintain efforts to strengthen sustainable development and use of suitable NSIs. Particularly because hospitals are obliged to provide the information requested and the scores are used for governmental quality regulation, pay-for-performance contracts and nursing care improvements. From the public health point of view, a peer-reviewing mechanism in which researchers and policy makers evaluate the creation and establishment of NSIs, is crucial. The purpose is to get insight into the development process and functioning, which will support the public health and scientific debate as well. The prioritising, selecting and development process seems to become increasingly transparent, but have not yet been crystallised or established entirely. Comparison against NSIs from other countries, including their descriptions and methodological issues, could be considered for future studies. We recommend a standardised format for publishing the methodological quality and characteristics of NSIs.

\subsection{Research limitations}

This study focuses on the methodological quality of Dutch NSIs. We used the AIRE instrument for the assessment. Although the agreement between the researchers was substantial and moderate, the use of the AIRE instrument should be tested further in order to improve its reliability. Apart from that, the methodological appraisal of NSIs was based on information from publicly available documents. The development process was 
Kieft, R.A.M.M., Stalpers, D., Jansen, A.P.M., Francke, A.L., Delnoij, D.M.J. The methodologica/ quality of nurse-sensitive indicators in Dutch hospitals: a descriptive exploratory research study) Health Policy: 2018, 122(7), 755-764

not always described in detail, which should be allowed for when considering the implications of our findings.

\section{CONCLUSION}

The methodological quality of mandatory NSIs used in Dutch hospitals is less than optimal. Although the purpose and relevance of each individual nurse-sensitive indicator have been described, no detailed information about the criteria for selecting these topics is available. It is not clear which specific stakeholders participated and how their input was used. We found no information about the process of collecting and compiling scientific evidence. It is unclear whether and to what extent the usability of NSIs has been tested. It is therefore open to question whether the indicators are accurate enough to identify changes or improve nursing practice. This might be problematic because the scores are used for governmental quality regulation, pay-for-performance contracts and nursing care improvements. Appropriate methodologies and strategies in the development process of NSI and transparency about the process itself are both important issues for addressing inconsistency in the quality of NSIs and establishing a successful implementation. The way we assessed the methodological quality of NSIs might be useful for nursing researchers, professionals and policy makers developing and implementing NSIs.

\section{Conflict of interest statement}

The authors declare that they have no competing interests.

\section{Funding statement}

This work was not supported by a grant. It represents independent research.

\section{Acknowledgement}

The authors thank the researchers and policymakers for their participation and assistance with the data analysis.

\section{Appendix A. Supplementary data}

The following is Supplementary data to this article:

\section{REFERENCES}

[1] Defining Nursing. Royal College of Nursing (RCN); 2014. p. 1-31www.rcn.org.uk.

[2] Heslop L, Lu S. Nursing-sensitive indicators: a concept analysis. Journal ofAdvanced Nursing 2014;70:2469-82, http://dx.doi.org/10.1111/jan.12503.

[3] In: Doran D, editor. Nursing outcomes: The state of the science, second ed.Sudbury: Jones \& Bartlett; 2011.

[4] Burston S, Chaboyer W, Gillespie B. Nurse-sensitive indicators suitable to reflectnursing care quality: a review and discussion of issues. Journal of Clinical Nurs-ing 2014;23:1785-95, http://dx.doi.org/10.1111/jocn.12337.

[5] Idvall E, Rooke L, Hamrin E. Quality indicators in clinical nursing: areview of the literature. Journal of Advanced Nursing 1997;25:6-17, http://dx.doi.org/10.1046/j.1365-

2648.1997.1997025006.x.

[6] Griffiths P, Richardson A, Blackwell R. Outcomes sensitive to nursingservice quality in ambulatory cancer chemotherapy: systematic scop-ing review. European Journal of Oncology Nursing 2012;16:238-46, http://dx.doi.org/10.1016/j.ejon.2011.06.004.

[7] Rapin J, Amour DD, Dubois C. Indicators for evaluating the performance andquality of care of ambulatory care nurses. Nursing Research and Practice2015;2015:1-8, http://dx.doi.org/10.1155/2015/861239. Review. 
Kieft, R.A.M.M., Stalpers, D., Jansen, A.P.M., Francke, A.L., Delnoij, D.M.J. The methodological quality of nurse-sensitive indicators in Dutch hospitals: a descriptive exploratory research study) Health Policy: 2018, 122(7), 755-764

[8] Campbell SM, Braspenning J, Hutchinson A, Marshall M. Research methods usedin developing and applying quality indicators in primary care. Quality \& Safetyin Health Care 2002;11:358-64, http://dx.doi.org/10.1136/qhc.11.4.358.

[9] Savitz L, Jones C, Bernard S. Quality indicators sensitive to nurse staffing in acutecare settings. Advancedvances in Patient Safety: From Research to Implemen-tation 2005;4:375-86 http://handle.dtic.mil/100.2/ADA434760.

[10] Mueller C, Karon SL. ANA nurse sensitive quality indicators for long-term carefacilities. Journal of Nursing Care Quality 2004;19:39-47 http://www.ncbi.nlm.nih.gov/pubmed/14717147.

[11] Batalden PB, Davidoff F. What is quality improvement and how canit transform healthcare? Quality \& Safety in Health Care 2007;16:2-3, http://dx.doi.org/10.1136/qshc.2006.022046.

[12] Ettorchi-Tardy A, Levif M, Michel P. Benchmarking: a method for contin-uous quality improvement in health. Healthcare Policy 2012;7:e101-19, http://dx.doi.org/10.12927/hcpol.2012.22872.

[13] Tawfik-Shukor AR, Klazinga NS, Arah OA. Comparing health sys-tem performance assessment and management approaches in theNetherlands and Ontario, Canada. BMC Health Services Research 2007;7:25,http://dx.doi.org/10.1186/1472-6963-7-25.

[14] Boo S, Froelicher ES. Secondary analysis of national sur-vey datasets. Japan Journal of Nursing Science 2013;10:130-5,http://dx.doi.org/10.1111/j.1742-7924.2012.00213.x.

[15] Magee T, Lee SM, Giuliano KK, Munro B. Generating new knowledge from exist-ing data: the use of large data sets for nursing research. Nursing Research2006;55:S50-6, http://dx.doi.org/10.1097/00006199-200603001-00009.

[16] Rubin HR, Pronovost P, Diette GB. From a process of care to a measure: thedevelopment and testing of a quality indicator. International Journal for Qualityin Health Care 2001;13:489_ 96, http://dx.doi.org/10.1093/intqhc/13.6.489.

[17] Mainz J. Developing evidence-based clinical indicators: a state of the art meth-ods primer. International Journal for Quality in Health Care 2003;15(Suppl.1):i5-11, http://dx.doi.org/10.1093/intqhc/mzg084.

[18] Bankauskaite V, Dargent G. Health systems performance indicators: method-ological issues. Presup y Gasto Publico 2007;12:125-37.

[19] National Quality Forum. Review and update of guidance for evaluating evidenceand measure testing; 2013.

[20] Hoi E. The importance of being measurable: quantifying nursing quality. The Journal of Nursing Research 2008;1:1-5 http://repository.upenn.edu/cgi/viewcontent.cgi?article=1007\&context=josnr.

[21] National voluntary standards for nursing-sensitive care: An initial performancemeasure set. National Quality Forum; 2004

http://www.nursingworld.org/mainmenucategories/thepracticeofprofessionalnursing/patientsafet yquality/quality-organisations/NQF.html.

[22] Implementation guide for the NQF endorsed nursing-sensitive care measureset 2009. The Joint Commission; 2009.

[23] Monalvo I. The National Database of Nursing Quality Indicators(NDNQI). Online Journal of Issues in Nursing 2007;12 http://ojin.nursingworld.org/MainMenuCategories/ANAMarketplace/ANAPeriodicals/OJIN/Tableo fContents/Volume122007/No3Sept07/NursingQualitylndicators.html.

[24] Hannah K, White PA, Kennedy MA, Hammell N. C-HOBIC -standardizedinformation to support clinical practice and quality patient care acrossCanada. Nursing Informatics 2012;142 https://www.ncbi.nlm.nih.gov/pmc/articles/PMC3799147/\#.

[25] Canadian Health Outcomes for Better Information and Care (C-HOBIC), (n.d.)https://chobic.cna-aiic.ca/about/default e.aspx (Accessed 19 May 2018).

[26] The impact of nursing on patient clinical outcomes. Developing quality indi-cators to improve care. Scotland Edinburgh: NHS Quality Improvement;

2015,file:///C:/Users/PC/Downloads/Nursing Quality Indicators Report FINAL.pdf.

[27] Framework for national performance indicators for nursing and midwifery.Department of Health; 2015.

[28] The Dutch Healthcare Inspectorate (IGZ), The Dutch Healthcare InspectorateEnforcement framework. Guideline for implementing transparancy

[In Dutch: 
Kieft, R.A.M.M., Stalpers, D., Jansen, A.P.M., Francke, A.L., Delnoij, D.M.J. The methodologica/ quality of nurse-sensitive indicators in Dutch hospitals: a descriptive exploratory research study) Health Policy: 2018, 122(7), 755-764

IGZ-handhavingskader Richtlijn voor transparante handhaving], n.d.

http://www.igz.nl/Images/IGZHandhavingskader tcm294-371520.pdf.

[29] Long-term strategic policy plan for legitimate confidence in responsiblecare 2012-2015

[In Dutch: Meerjarenbeleidsplan. Voor gerechtvaardigdvertrouwen in verantwoorde zorg 2012-

2015]. Utrecht: The Dutch Healthcarelnspectorate (IGZ); 2011.

[30] Basic set of hospital quality indicators 2015

[In Dutch: KwaliteitsindicatorenBasisset Ziekenhuizen 2015]. The Dutch Healthcare Inspectorate

(IGZ); 2014http://www.igz.nl//mages/Basisset ziekenhuizen20152 tcm294-359756.pdf.

[31] Guide to inpatient quality indicators: quality of care in hospitals -volume, mor-tality, and utilization. Agency for Healthcare Research and Quality (AHRQ);2012.

[32] De Koning DJ, Smulders DA, Klazinga PDN. Appraisal of indicators throughresearch and evaluation. AIRE); 2007.

[33] Pasman H, Brandt H, Deliens L, Francke A. Quality indicators for pallia-tive care: a systematic review. Journal of Pain and Symptom Management2009;38:145-56, http://dx.doi.org/10.1016/j.jpainsymman.2008.07.008.

[34] de Roo M, Leemans K, Claessen S, Cohen J, Pasman R, Keliens L,et al. Quality indicators for palliative care: update of a systematicreview. Journal of Pain and Symptom Management 2013;46:556-72,http://dx.doi.org/10.1016/j.jpainsymman.2012.09.013.

[35] Smeulers M, Verweij L, Maaskant JM, De Boer M, Krediet CTP, NieveenVan Dijkum EJM, et al. Quality Indicators for safe medication prepara-tion and administration: a systematic review. PLoS One 2015;10:1-14,http://dx.doi.org/10.1371/journal.pone.0122695.

[36] Leading better care report of the senior charge nurse review and clinical qualityindicators project. Scottish Government; 2008 http://www.gov.scot/resource/doc/225218/0060938.pdf.

[37] Delnoij DMJ, J.J.D.J.M Rademakers, Groenewegen PP. The Dutch con-sumer quality index: an example of stakeholder involvement inindicator development. BMC Health Services Research 2010;10:88,http://dx.doi.org/10.1186/1472-6963-10-88.

[38] Kötter T, Schaefer FA, Scherer M, Blozik E. Involving patients in quality indi-cator development? A systematic review. Patient Preference and Adherence2013;7:259-68, http://dx.doi.org/10.2147/PPA.S39803.

[39] Hardt DiCuccio M. The relationship between patient safety culture and patientoutcomes: a systematic review. Journal of Patient Safety 2015;11:135-

42,http://dx.doi.org/10.1097/PTS.0000000000000058.

[40] Stalpers D, de Brouwer BJM, Kaljouw MJ, Schuurmans MJ. Associ-ations between characteristics of the nurse work environment andfive nurse-sensitive patient outcomes in hospitals: a systematic reviewof literature. International Journal of Nursing Studies 2015;52:817-35,http://dx.doi.org/10.1016/j.ijnurstu.2015.01.005.

[41] Safety management programme, practice guide early recognition andtreatment of pain [In Dutch: VMS Praktijkgids Vroege herkenning en behan-deling van pijn]; 2009 http://www.vmszorg.nl/ library/5544/web 2009.0109praktijkgids pijn.pdf.

[42] Safety management programme, practice guide vulnerable elderly [in Dutch:VMS Praktijkgids Kwetsbare ouderen]; 2009 http://www.vmszorg.nl/ library/5540/web 2009.0104 praktijkgids kwetsbare ouderen.pdf.

[43] Van Nie-Visser NC, Schols JMGA, Meesterberends E, Lohrmann C, Mei-jers JMM, Halfens RJG. An international prevalence measurement ofcare problems: study protocol. Journal of Advanced Nursing 2013;69,http://dx.doi.org/10.1111/jan.12190.

[44] Halfens RJG, Meesterberends E, Neyens JCL. Landelijke Prevalentiemeting Zorg-problemen Rapportage resultaten, 2015; 2015.

[45] Kieft RA, de Brouwer BBJM, Francke AL, Delnoij DMJ. How nurses andtheir work environment affect patient experiences of the quality ofcare: a qualitative study. BMC Health Services Research 2014;14:249,http://dx.doi.org/10.1186/1472-6963-14-249.

[46] Vuokko R, Mäkelä-Bengs P, Hyppönen H, Doupi P. Secondary useof structured patient data: interim results of a systematic review.Studies in Health Technology and Informatics 2015;210:291-5,http://dx.doi.org/10.3233/978-1-61499-512-8-291.

[47] Hovenga E, Grain H. An information paradigm shift is required to realizeEHR benefits. Studies in Health Technology and Informatics 2015;216:26-9, http://dx.doi.org/10.3233/978-161499-564-7-26.

[48] Galster G. Why is clinical information not reused? Stud-ies in Health Technology and Informatics 2012;180:624-8, http://dx.doi.org/10.3233/978-1-61499-101-4-624. 
Kieft, R.A.M.M., Stalpers, D., Jansen, A.P.M., Francke, A.L., Delnoij, D.M.J. The methodological quality of nurse-sensitive indicators in Dutch hospitals: a descriptive exploratory research study) Health Policy: 2018, 122(7), 755-764

\section{TABLES AND FIGURES}

Table 1. The Appraisal of Indicators through Research and Evaluation tool (domains and items).

\section{Domain 1: Purpose, relevance and organisational entity}

1. The purpose of the indicator is described clearly

2. The criteria for selecting the topic of the indicator are described in detail

3. The organizational context of the indicator is described in detail

4. The quality domain the indicator addresses is described in detail

5. The health-care process covered by the indicator is described and defined in detail

Domain 2: Stakeholder involvement in the development process

6. The group developing the indicator includes individuals from all relevant professional groups

7. Considering the purpose of the indicator, all relevant stakeholders have been involved at some stage of the development process

8. The indicator has been formally endorsed

\section{Domain 3: Scientific evidence}

9. Systematic methods were used to search for scientific evidence

10. The indicator is based on recommendations from an evidence-based guideline or studies published in peer-reviewed scientific journals

11. The supporting evidence has been critically appraised

Domain 4: Additional evidence, formulation and usage

12. The numerator and denominator are described in detail

13. The target patient population of the indicator is defined clearly

14. A strategy for risk adjustment has been considered and described

15. The indicator measures what it is intended to measure (validity)

16. The indicator measures accurately and consistently (reliability)

17. The indicator has sufficient discriminative power

18. The indicator has been piloted in practice

19. The efforts needed for data collection have been considered

20. Specific instructions for presenting and interpreting results

Table 2. Overview of the mandatory NSIs (2015).

Hospital care: mandatory NSIs (2015)

Wound care: Wound expertise centre

Wound care: Diabetic foot classified by the Texas classification

Malnutrition: Screening for malnutrition (children)

Malnutrition: Treatment of malnutrition (adults and children)

Delirium: Risk assessment for delirium

Delirium: Screening for and observation of delirium

Pain: Hospital-wide patient standardised pain assessment 
Kieft, R.A.M.M., Stalpers, D., Jansen, A.P.M., Francke, A.L., Delnoij, D.M.J. The methodological quality of nurse-sensitive indicators in Dutch hospitals: a descriptive exploratory research study? Health Policy: 2018, 122(7), 755-764

Fig. 1. Example of the calculation procedure.

\section{Example}

If 4 researchers give the following scores for Domain 2:

\begin{tabular}{ccccc} 
& Item 6 & Item 7 & Item 8 & Total \\
Researcher 1 & 3 & 2 & 3 & $\mathbf{8}$ \\
Researcher 2 & 2 & 2 & 3 & 7 \\
Researcher 3 & 2 & 2 & 3 & 7 \\
Researcher 4 & 2 & 2 & 3 & 7 \\
\hline Total & $\mathbf{9}$ & $\mathbf{8}$ & $\mathbf{1 2}$ & $\mathbf{2 9}$
\end{tabular}

Maximum possible score $=4$ (strongly agree) $\times 3$ (items) $\times 4$ (researchers) $=48$

Minimum possible score $=1$ (strongly disagree) $\times 3$ (items) 4 (researchers) $=12$

The scaled domain score will be:

$\frac{\text { Obtained score }- \text { Minimum possible score }}{\text { Maximum possible score }- \text { Minimum possible score }} \times 100 \%$

$$
\frac{29-12}{48-12} \times 100=\frac{17}{36} \times 100=0.4722 \times 100 \%=47 \%
$$

Fig. 2. Overview of domain scores assessed with the AIRE instrument.

$\begin{array}{lccccc}\text { National basic set of Dutch NSI (2015) } & \text { Domain 1 } & \text { Domain 2 } & \text { Domain 3 } & \text { Domain 4 } & \text { Range (NSI-level) } \\ \text { Wound care: Wound expertise centre } & 55 \% & 47 \% & 31 \% & 40 \% & 31 \%-55 \% \\ \text { Wound care: Diabetic foot classified by the Texas classification } & 52 \% & 47 \% & 19 \% & 18 \% & 18 \%-52 \% \\ \text { Malnutrition: Screening for malnutrition (children) } & 52 \% & 28 \% & 11 \% & 22 \% & 11 \%-52 \% \\ \text { Malnutrition: Treatment of malnutrition (adults and children) } & 53 \% & 22 \% & 25 \% & 25 \% & 22 \%-53 \% \\ \text { Delirium: Risk assessment for delirium } & 52 \% & 47 \% & 31 \% & 22 \% & 22 \%-52 \% \\ \text { Delirium: Screening for and observation of delirium } & 53 \% & 42 \% & 36 \% & 36 \% & 36 \%-53 \% \\ \text { Pain: Hospital-wide standardised pain assessments } & 52 \% & 50 \% & 22 \% & 37 \% & 22 \%-52 \% \\ \text { Range (domain level) } & 52 \%-55 \% & 22 \%-50 \% & 11 \%-36 \% & 18 \%-40 \%\end{array}$


Kieft, R.A.M.M., Stalpers, D., Jansen, A.P.M., Francke, A.L., Delnoij, D.M.J. The methodological quality of nurse-sensitive indicators in Dutch hospitals: a descriptive exploratory research study) Health Policy: 2018, 122(7), 755-764

Table 3. Indicator questions of the NSI "diabetic foot classified by the Texas classification".

\begin{tabular}{|l|}
\hline Diabetic foot classified by the Texas classification \\
\hline Indicator questions: \\
\hline 1. Does the hospital treat patients with a diabetic foot? Yes/No \\
\hline 2. Is the care for the patients included spread over multiple locations? Yes/No \\
\hline 3. Is the number of patients with a diabetic foot documented? Yes/No \\
\hline 4. Are patients with a diabetic foot classified using the Texas classification? Yes/No \\
\hline 5. If not, with which other classification are patients with a diabetic foot documented? \\
\hline 6. How many patients are classified as grade 1 (Superficial wound, not involving tendon, \\
capsule or bone)? \\
\hline 7. How many patients are classified as grade 2 (Wound penetrating to tendon or capsule)? \\
\hline 8. How many patients are classified as grade 3 (Wound penetrating to bone or joint)? \\
\hline 9. Is the wound expertise centre consulted when treating patients with a diabetic foot? \\
\hline
\end{tabular}

Fig. 3. Screening and treatment of malnutrition: numerator and denominator.

1. Screening for malnutrition (children)

a) The percentage of children screened for malnutrition

- Number of children screened for acute malnutrition during admission

- Denominator: number of children admitted during the reporting year

b) The percentage of children classified as having acute malnutrition

- Numerator: percentage of children classified as having acute malnutrition

- Denominator: number of children screened for acute malnutrition during admission

2. Treatment of malnutrition (adults and children)

a) Percentage of severely malnourished adults with an appropriate protein intake

- Numerator: number of severely malnourished adults with an appropriate protein intake on the fourth day of admission

- Denominator: number of severely malnourished adults on the fifth day of admission

b) Percentage of acutely malnourished children with an adequate protein intake

- Number of malnourished children with an adequate protein intake on the fourth day of admission

- Denominator: number of severely malnourished children on the fifth day of admission

c) Percentage of acutely malnourished children with an adequate energy intake.

- Numerator: number of malnourished children with an adequate energy intake on the fourth day of admission

- Denominator: number of severely malnourished children on the fifth day of admission 
Kieft, R.A.M.M., Stalpers, D., Jansen, A.P.M., Francke, A.L., Delnoij, D.M.J. The methodological quality of nurse-sensitive indicators in Dutch hospitals: a descriptive exploratory research study? Health Policy: 2018, 122(7), 755-764

Fig. 4. Risk assessment and screening for \& observation of delirium: numerator and denominator.

\section{NSI Delirium (numerators and denominators)}

1. Risk assessment for delirium

- Numerator: the number of nursing wards where over $80 \%$ of all patients (aged 70 or older) have a delirium risk score recorded on admission in the medical records.

- Denominator: the number of nursing wards to which patients aged 70-plus are admitted at any time during the record year,

2. Screening for and observation of delirium;

- Numerator: number of patients assessed at least once for delirium by the Delirium Observation Screening Scale (DOSS) (regardless of outcome)

- Denominator: number of patients assessed by the method of indicator 1 and who have a high risk of developing delirium (numerator of indicator 1), along with patients who were assessed by other means and have a high risk of developing delirium 